\title{
Correction to: Counterfactual inference for consumer choice across many product categories
}

\section{Robert Donnelly ${ }^{1}$ Francisco J. R. Ruiz ${ }^{2,3} \cdot$ David Blei $^{2} \cdot$ Susan Athey ${ }^{1}$}

Published online: 27 December 2021

๑) Springer Science+Business Media, LLC, part of Springer Nature 2021

\section{Correction to: Quantitative Marketing and Economics https://doi.org/10.1007/s11129-021-09241-2}

In the recently published paper, the affiliations of Dr Francisco J.R. Ruiz were captured incorrectly. The correct affiliations are:

${ }^{2}$ Columbia University, New York, NY 10027, USA

${ }^{3}$ University of Cambridge, Cambridge, CB2 1TN, UK

The original article has been corrected.

Publisher's Note Springer Nature remains neutral with regard to jurisdictional claims in published maps and institutional affiliations.

The original article can be found online at https://doi.org/10.1007/s11129-021-09241-2.

Susan Athey

athey@stanford.edu

1 Stanford University, 655 Knight Way, Stanford, CA 94305, USA

2 Columbia University, New York, NY 10027, USA

3 University of Cambridge, Cambridge CB2 1TN, UK 